\title{
Serum cyclin-dependent kinase 9 is a potential biomarker of atherosclerotic inflammation
}

\author{
Yeming Han ${ }^{1}$, Shanshan Zhao², Yaoqin Gong ${ }^{2,3}$, Guihua Hou ${ }^{2}$, Xi Li ${ }^{2,3, *}$, Li Li ${ }^{1, *}$ \\ ${ }^{1}$ Key Laboratory of Cardiovascular Remodeling and Function Research, Chinese Ministry of Education and Chinese Ministry of \\ Health, Department of of Cardiology, Qilu Hospital, Shandong University, Jinan, Shandong, 250012, China \\ ${ }^{2}$ Laboratory of Experimental Teratology, Ministry of Education, School of Medicine, Shandong University, Jinan, Shandong, \\ 250012, China \\ ${ }^{3}$ Department of Genetics, School of Medicine, Shandong University, Jinan, Shandong, 250012, China \\ *These authors contributed equally to this work
}

Correspondence to: Li Li, e-mail: lilihospital@163.com

Keywords: atherosclerosis, inflammation, serum, proteomics, CDK9

Received: July 29, $2015 \quad$ Accepted: November 16, $2015 \quad$ Published: December 01,2015

\section{ABSTRACT}

Atherosclerotic coronary artery disease (CAD) is one of the most prevalent diseases worldwide. Atherosclerosis was considered to be the single most important contributor to CAD. In this study, a distinct serum protein expression pattern in CAD patients was demonstrated by proteomic analysis with two-dimensional gel electrophoresis coupled with mass spectrometry. In particular, CDK9 was found to be highly elevated in serum, monocytes and artery plaque samples of CAD patients. Furthermore, there was high infiltration of CD14+ monocytes/macrophages within artery plaques correlated with the expression of CDK9. Moreover, Flavopiridol (CDK9 inhibitor) could inhibit THP-1 cell (monocytic acute leukemia cell line) proliferation by targeting CDK9. Altogether, These findings indicate that CDK9 represent an important role for inflammation in the pathogenesis of atherosclerosis. It may be a potential biomarker of atherosclerotic inflammation and offer insights into the pathophysiology and targeted therapy for atherosclerotic CAD.

\section{INTRODUCTION}

Coronary artery disease (CAD) is a leading cause of morbidity and mortality and has an increasing incidence worldwide [1]. Atherosclerosis was traditionally considered a metabolic disease characterized by the accumulation of lipids and fibrous elements in the large arteries, and constituted the single most important contributor to CAD $[2,3]$. In the current view, accumulating evidences support a critical role for inflammation in the pathogenesis of atherosclerosis. Several studies have demonstrated that C-reactive protein $[4,5]$, B-type natriuretic peptide (NT-pro-BNP) [6], and serum cardiac troponin I (cTN-I) [7] as robust serum biomarkers for CAD risk.

Recent studies [8-10] have demonstrated that cyclin-dependent kinase 9 (CDK9) plays a crucial role in regulation of the cell cycle and monitoring the activation of primary inflammatory response genes. An increasing number of inhibitors, such as flavopiridol (FLA), have developed towards therapeutic applications in cancer and inflammation by targeting CDK9 [11-13].
Nonetheless, there were fewer researches for CDK9 in the atherosclerotic inflammation or atherosclerotic CAD.

In our previous study (unpublished data), results of the 2-D proteomics analysis revealed that CDK9 was highly expressed in the serum of patients with atherosclerotic CAD. Herein, the aim of this study was to analyze the expression levels of CDK9 in serum, monocytes, and plaque samples of atherosclerotic CAD patients and to explore the possible benefits in the prognosis and treatment of atherosclerotic CAD.

\section{RESULTS}

Proteomic analysis of serum samples of atherosclerotic CAD patients and healthy controls

To identify aberrant serum proteins during atherosclerosis, we compared serum samples from atherosclerotic CAD patients and healthy control subjects. Figure 1 showed silver-stained 2-D electrophoresis IPG standard maps from one representative experiment with 
the two sample types. Spot analysis using 2-D PDQuest (Bio-Rad) detected $509 \pm 31$ spots per patient sample (Figure 1A) and $565 \pm 29$ spots per healthy control sample (Figure 1B). The protein expression was considered to have changed if the percentage volume of its spots on the gels showed a two-fold or greater difference $(P<0.05)$. Thirty-three differentially expressed proteins between the atherosclerotic CAD patient and healthy control were excised from the 2-D gels, digested in the gel and applied to a sample template for MALDI-TOF mass spectrometry. Twenty-seven protein spots were successfully identified with Mascot using peptide mass fingerprinting data. The protein names, NCBI accession numbers, theoretical molecular weight and $\mathrm{pI}$ values were shown in Table 1. Among 27 proteins identified, 15 of them, including CDK9, were increased, whereas 12 proteins were decreased in atherosclerotic serum samples.

All 27 identified proteins were further classified into 6 different groups based on cell proliferation and apoptosis, inflammation factor, immune factor, energy metabolism and signaling pathway according to known or postulated functions and pathways (Table 2). CDK9 is the following emphasis of this study.

\section{Validation of CDK9 expression in serum samples}

As shown in Figure 2A and 2B, CDK9 expression was found to be significantly increased in atherosclerotic patients compared with those in healthy controls $(P<0.01)$ in Western blotting assays. Figure $2 \mathrm{C}$ showed a

A

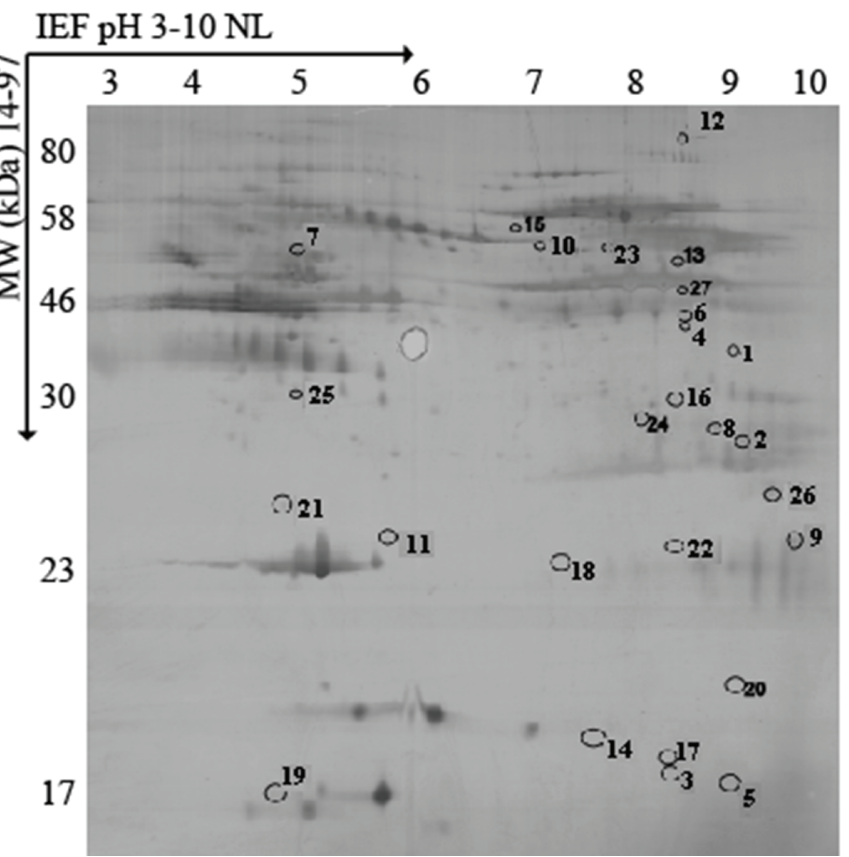

2.2-fold CDK9 increase in atherosclerotic serum samples measured with ELISA ( $P<0.05$, vs. Controls). Their characteristics (including proteomic analysis samples) are summarized in Supplementary Table S1.

\section{Validation of CDK9 expression in peripheral blood mononuclear cells (PBMCs)}

We isolated PBMCs from atherosclerotic patients and healthy controls to measure CDK9 expression. As shown in Figure $3 \mathrm{~A}$ and $3 \mathrm{~B}$, both mRNA and protein levels of CDK9 were found to be significantly increased in PBMCs of atherosclerotic patients compared with healthy controls. In addition, CDK9 was higher expressed in monocyte subpopulations than in lymphocyte subpopulations in PBMCs of atherosclerotic patients compared with healthy controls $(P<0.01$, Figure $3 \mathrm{C})$.

\section{CDK9 expression in atherosclerotic plaques}

In order to further investigate whether CDK9 was increased in atherosclerotic process, artery plaque tissue sections were analyzed by immunohistochemistry staining. As shown in Figure 4 (and Supplementary Figure 1), compared with non-plaque tissue, plaque tissue showed irregular intimal thickening, calcification, and significant atherosclerotic plaque formation, along with infiltration of abundant inflammatory cells. CDK9 positive expression was found in atherosclerotic plaque intima mainly located within nucleus. Furthermore, the CD14 (monocyte/ macrophage surface marker) immunohistochemistry
B

\section{IEF $\mathrm{pH} 3-10 \mathrm{NL}$}

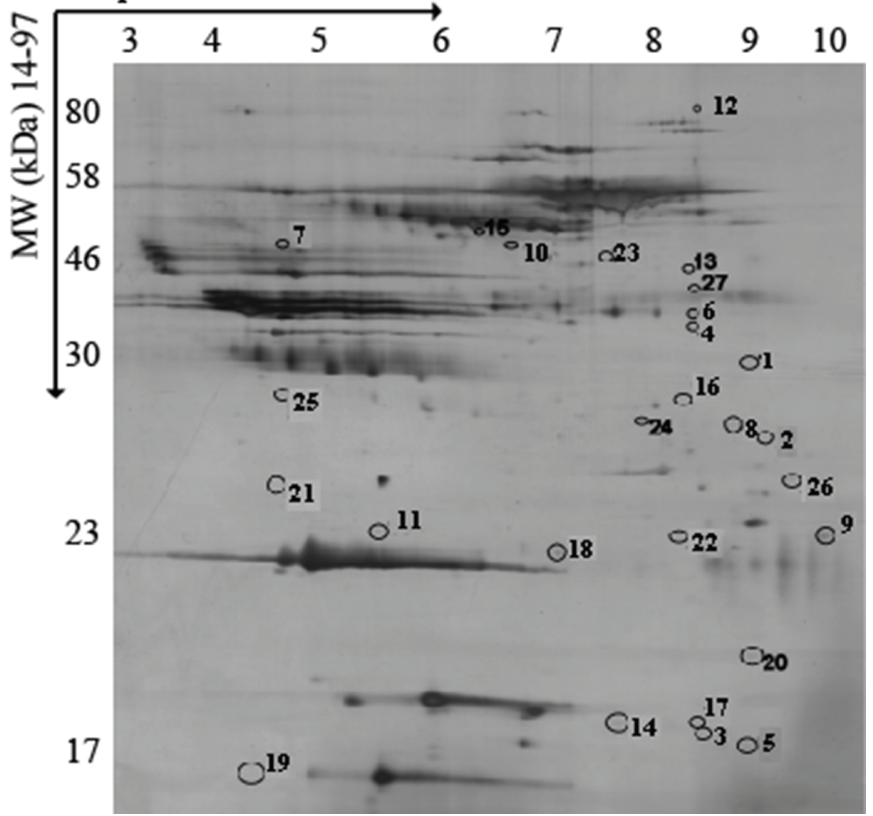

Figure 1: 2-D electrophoretograms of serum sample. (A) Atherosclerotic patients. (B) Healthy control subjects. The gels were silver stained and analyzed using PDQuest 2-D by Bio-Rad. Differentially expressed proteins are marked with numbers in the gel maps. 
Table 1: Identification of differentially expressed proteins in atherosclerotic patients compared with healthy controls

\begin{tabular}{|c|c|c|c|c|}
\hline No. & Name & MW & pI & NCBI accession number \\
\hline \multicolumn{5}{|c|}{ Upregulated proteins } \\
\hline 1 & $\begin{array}{l}\text { Angiotensin II receptor type-1 (clone HATR1GH) } \\
\text {-human }\end{array}$ & 41142 & 9.15 & 627378 \\
\hline 2 & T-cell receptor delta chain, CDR3 region & 32819 & 8.96 & 4151024 \\
\hline 4 & Cyclin-dependent kinase 9 & 42777 & 8.97 & 4502747 \\
\hline 7 & Caspase 8 isoform $\mathrm{E}$ [Homo sapiens] & 55391 & 4.99 & 15718712 \\
\hline 8 & Abhydrolase domain containing 10 & 33932 & 8.81 & 15778873 \\
\hline 12 & TNF receptor-associated protein 1 & 80109 & 8.3 & 23272132 \\
\hline 13 & $\begin{array}{l}\text { Isocitrate dehydrogenase } 2 \text { (NADP }+ \text { ), } \\
\text { mitochondrial precursor }\end{array}$ & 50909 & 8.88 & 28178832 \\
\hline 15 & $\begin{array}{l}\text { Phosphatidylinositol 4-phosphate 5-kinase type } \\
2 \text { alpha }\end{array}$ & 61036 & 6.39 & 32167383 \\
\hline 16 & $\begin{array}{l}\text { Ankynin repeat and SocS box-containing protein } \\
7 \text { isoform } 2\end{array}$ & 36011 & 8.57 & 38176283 \\
\hline 18 & Interleukin 1 family, member 10 & 16943 & 4.94 & 74355171 \\
\hline 23 & $\begin{array}{l}\text { NADH dehydrogenase (ubiquinone) Fe-S protein } \\
4\end{array}$ & 52545 & 7.21 & 119573011 \\
\hline 24 & $\begin{array}{l}\text { CD80 antigen (CD28 antigen ligand 1, B7-1 } \\
\text { antigen) }\end{array}$ & 33047 & 7.55 & 119599971 \\
\hline 25 & Cyclin D-type binding-protein 1 & 40261 & 4.71 & 119612996 \\
\hline 26 & Coenzyme Q4 homolog & 29638 & 9.29 & 166795285 \\
\hline 27 & Mast cell carboxypeptidase A; MC-CPA & 48669 & 9.08 & 317373331 \\
\hline \multicolumn{5}{|c|}{ Downregulated proteins } \\
\hline 3 & $\begin{array}{l}\text { ADP-ribosylation factor guanine nucleotide } \\
\text { factor } 6 \text { isoform } 6(\mathrm{ARF} 6)\end{array}$ & 19950 & 9.04 & 4502211 \\
\hline 5 & Chemokine-like factor isoform c & 17169 & 9.41 & 7705933 \\
\hline 6 & WW45 protein & 44633 & 9.12 & 10862824 \\
\hline 9 & G6B protein isoform G6b-C precursor & 26147 & 9.68 & 19913377 \\
\hline 10 & $\begin{array}{l}\text { Neuropilin-and tolloide-like protein isoform } 1 \\
\text { precusor }\end{array}$ & 57871 & 6.37 & 20452470 \\
\hline 11 & Glutathione S-transferase M5 & 23442 & 5.67 & 23065563 \\
\hline 14 & Interleukin-19 isoform 2 precursor & 20451 & 7.62 & 30795208 \\
\hline 17 & Interleukin 20 precursor & 20072 & 8.92 & 47481041 \\
\hline 19 & Interferon, alpha 14 [Homo sapiens] & 22062 & 6.82 & 50960346 \\
\hline 20 & Mast cell-expressed membrane protein 1 & 21228 & 9.03 & 109698611 \\
\hline 21 & Dendritic cell-derived ubiquitin-like protein & 26189 & 5.45 & 109896149 \\
\hline 22 & $\begin{array}{l}\text { Tumor necrosis factor ligand superfamily } \\
\text { member } 8\end{array}$ & 26017 & 7.62 & 109896149 \\
\hline
\end{tabular}


Table 2: Classification of known proteins

\begin{tabular}{|c|c|}
\hline Category & Protein Name \\
\hline \multirow{5}{*}{ Cell Cycle, Proliferation and Apoptosis } & Cyclin-dependent kinase 9 \\
\hline & Caspase 8 isoform E [Homo sapiens] \\
\hline & Phosphatidylinositol 4-phosphate 5-kinase type 2 alpha \\
\hline & Cyclin D-type binding-protein 1 \\
\hline & WW45 protein \\
\hline \multirow{4}{*}{ Inflammation Factor } & Chemokine-like factor isoform c \\
\hline & TNF receptor-associated protein 1 \\
\hline & Interleukin 1 family, member 10 \\
\hline & Interferon, alpha 14 [Homo sapiens] \\
\hline \multirow{7}{*}{ Immune Factor } & T-cell receptor delta chain, CDR3 region \\
\hline & Interleukin-19 isoform 2 precursor \\
\hline & Interleukin 20 precursor \\
\hline & Mast cell-expressed membrane protein 1 \\
\hline & Dendritic cell-derived ubiquitin-like protein \\
\hline & CD80 antigen (CD28 antigen ligand 1, B7-1 antigen) \\
\hline & Mast cell carboxypeptidase A; MC-CPA \\
\hline \multirow{5}{*}{ Energy Metabolism } & Isocitrate dehydrogenase $2(\mathrm{NADP}+)$, mitochondrial precursor \\
\hline & NADH dehydrogenase (ubiquinone) Fe-S protein 4 \\
\hline & ADP-ribosylation factor guanine nucleotide factor 6 isoform 6(ARF6) \\
\hline & Neuropilin-and tolloide-like protein isoform 1 precusor \\
\hline & coenzyme Q4 homolog \\
\hline \multirow{3}{*}{ Signaling Pathway } & Abhydrolase domain containing 10 \\
\hline & Glutathione S-transferase M5 \\
\hline & Ankynin repeat and SocS box-containing protein 7 isoform 2 \\
\hline \multirow{3}{*}{ Other Categories } & G6B protein isoform $\mathrm{G} 6 \mathrm{~b}-\mathrm{C}$ precursor \\
\hline & Tumor necrosis factor ligand superfamily member 8 \\
\hline & Angiotensin II receptor type-1 (clone HATR1GH) -human \\
\hline
\end{tabular}

staining showed positive staining within atherosclerotic plaques which represented the majority of inflammatory infiltration cells. Moreover, the $\mathrm{CD} 14^{+}$cells showed increased CDK9 levels in atherosclerotic plaques, which indicated the role of CDK9 in monocyte infiltration during atherosclerosis.

\section{Inhibition of CDK9 expression by FLA in THP-1 cells}

Because CDK9 was significantly increased in atherosclerotic patients and has been shown to be inhibited by FLA, the physiological properties of CDK9 treated with FLA were further investigated in THP-1 cells (human monocytic acute leukemia cell line). As shown in Figure 5A and 5B, CDK9 protein expression was decreased with FLA $(100 \mathrm{nM})$ treatment combined with $\mathrm{TNF} \alpha(50 \mathrm{ng} / \mathrm{mL})$ stimulation for $6 \mathrm{~h}$ and $24 \mathrm{~h}$.

To study the significance of the FLA-dependent suppression of CDK9 expression, THP-1 cells were treated with FLA (50 or $100 \mathrm{nM}$ ) combined with TNFa stimulation in CCK-8 assays. The dose of $100 \mathrm{nM}$ FLA showed an apparent inhibitory effect at either $6 \mathrm{~h}$ or $24 \mathrm{~h}$ of $\mathrm{TNF} \alpha$-stimulated proliferation (Figure 5C). To determine the effect of CDK9 on monocyte apoptosis, flow cytometry analysis of THP-1 cells was performed with Annexin V-PI staining. As shown in Figure 5D and 5E, both the percentages of early and late apoptosis were significantly 
A

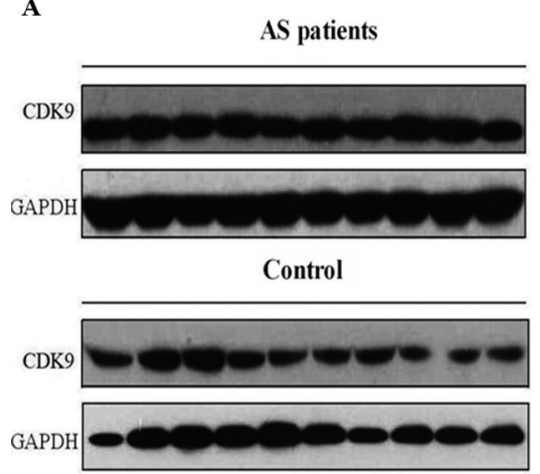

B

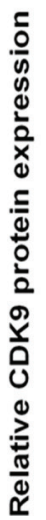

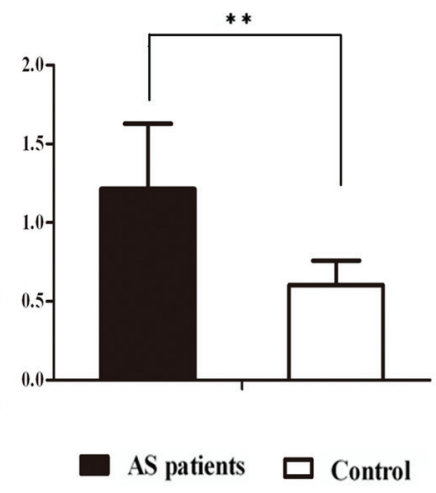

C

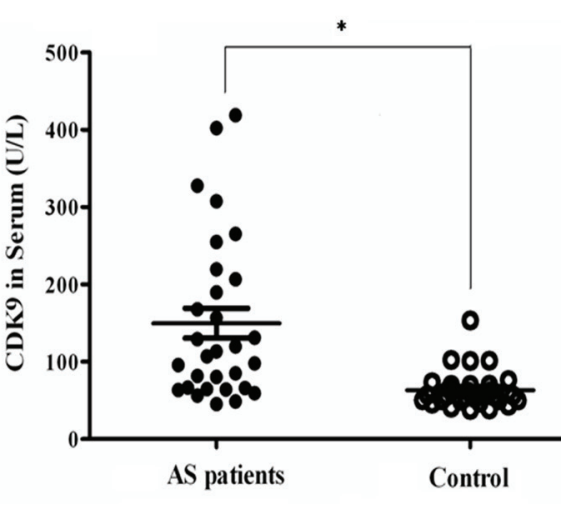

Figure 2: Validation of CDK9 expression in serum samples. (A) Representative image of Western-blotting assay. (B) The relative expression of CDK9 protein (Columns, means; Bars, \pm S.D.; **P $<0.01,30$ atherosclerotic patients, 25 healthy controls. (C) CDK9 level detected with ELISA (Columns, means; Bars, \pm S.D.; $* P<0.05,30$ atherosclerotic patients, 25 healthy controls).

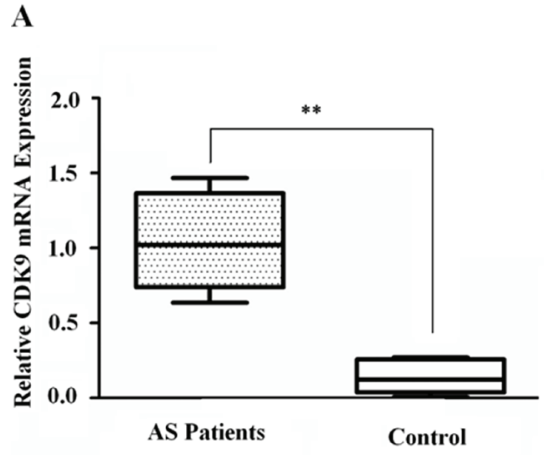

B

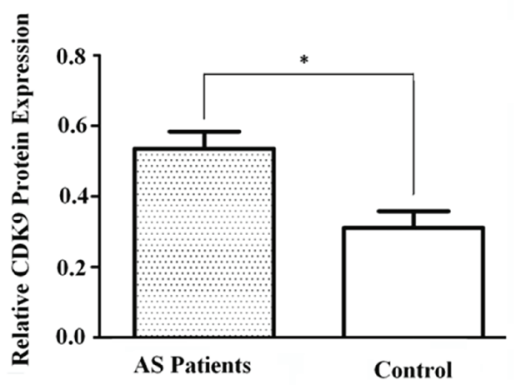

C

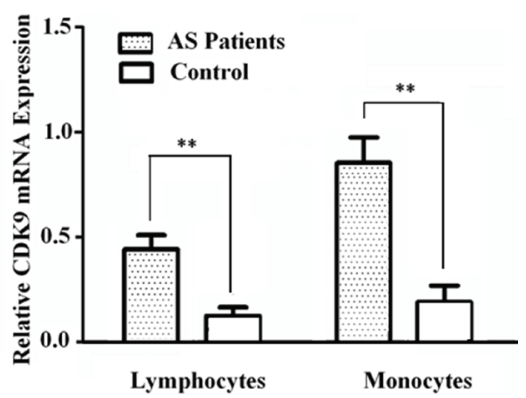

Figure 3: Validation of CDK9 expression in PBMCs. (A) Elevated mRNA expression was found in atherosclerotic patients (Columns, means; Bars, \pm S.D.; ** $P<0.01 ; n=5$ ). (B) Consistent with mRNA expression, elevated CDK9 protein level was found in atherosclerotic patients (Columns, means; Bars, \pm S.D.; ${ }^{*} P<0.05 ; n=5$ ). (C) Both lymphocytes and monocytes expressed CDK9, while monocytes showed higher levels than lymphocytes (Columns, means; Bars, \pm S.D; $* * P<0.01 ; n=5$ ).

H\&E
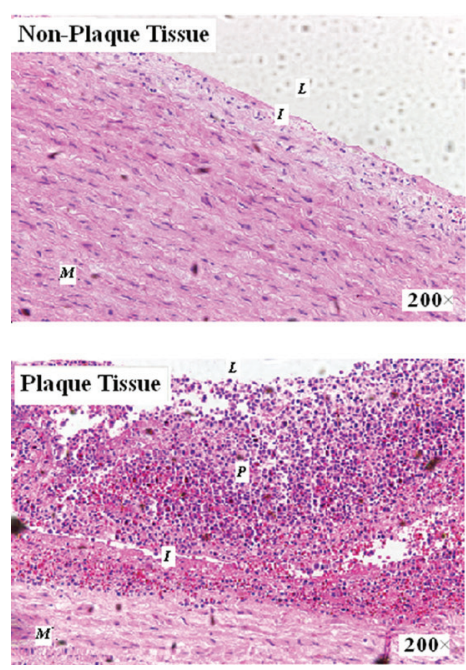

CDK9
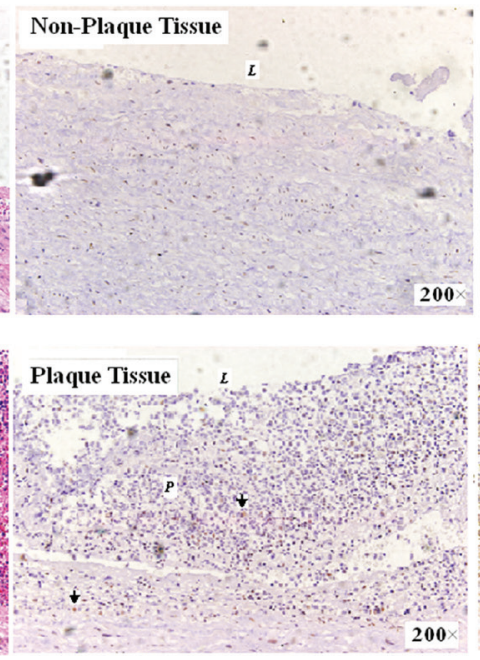

CD14
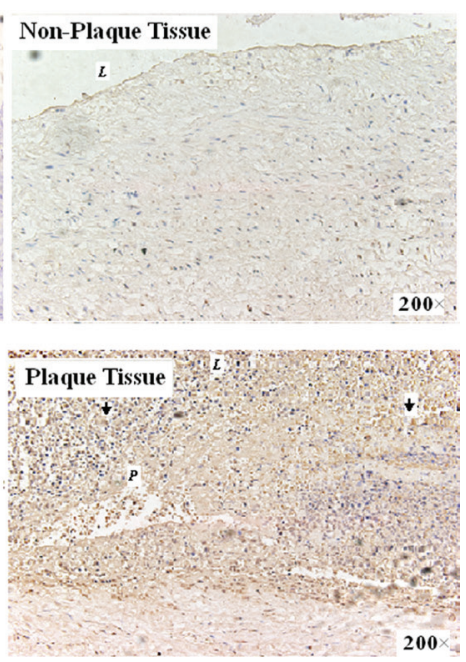

Figure 4: Immunohistochemistry staining of CDK9 and CD14 in artery wall sections (magnification $200 \times$ ). H \& E staining (left), CDK9 staining (middle) and CD14 staining (right). CDK9 expression was found mainly in nucleus on the area of plaque tissues (Arrow); CD14 expression was found mainly in cell membrane and cytoplasm on the area of plaque tissues (Arrow). M = Muscle; $\mathrm{I}=$ Intima; $\mathrm{P}=$ Plaque and $\mathrm{L}=$ Lumen. 
increased with FLA $(100 \mathrm{nM})$ treatment combined with TNF $\alpha(50 \mathrm{ng} / \mathrm{mL})$ stimulation. This result confirmed that FLA inhibits gene expression and potentiates tumor necrosis factor (TNF)-induced apoptosis.

In addition, we examined the cell cycle after FLA (100 nM) treatment with flow cytometry. As shown in Supplementary Figure 2, FLA treatment for $6 \mathrm{~h}$ might cause $\mathrm{G} 2 / \mathrm{M}$ arrest (the percentage of $\mathrm{G} 2 / \mathrm{M}$ cells from $10.9 \%$ to $12.6 \%$ ). FLA treatment increased the percentage of $\mathrm{G} 2 / \mathrm{M}$ cells to $15.2 \%$ under TNF $\alpha$ stimulation. However, there was no significant difference detected between groups for the percentage of cells in $\mathrm{G}_{0} / \mathrm{G}_{1}$ or S phase.

\section{DISCUSSION}

The hallmark of the cyclin-dependent kinase is its ability to modulate cell cycle [14-16]. The member of the family, CDK9, was discovered by its ability involved in the control of gene transcription. The positive transcriptional elongation factor $\mathrm{b}(\mathrm{P}-\mathrm{TEFb})$, which regulates the elongation phase of RNA-polymerase II-dependent transcription, is a heterodimer composed of
CDK9 and cyclin T1 $[17,18]$. Of note, dysfunctions in the CDK9-related pathway are related with several forms of human tumors [15, 19-24]. In addition, the roles of CDK9 in acquired immunodeficiency syndrome (AIDS) and cardiac hypertrophy have been reported [25-27].

Increasing evidences have shown that CDK9 is increased in activated lymphocytes, which has a critical role in inflammatory disorders [28-30]. In the present study, a distinct serum protein expression pattern in atherosclerotic CAD patients was demonstrated. In particular, CDK9 was found to be highly elevated in serum, monocytes and artery plaque samples of atherosclerotic CAD patients. Furthermore, there was high infiltration of $\mathrm{CD}_{14}{ }^{+}$monocytes/macrophages within artery plaques correlated with the expression of CDK9. These findings indicated that CDK9 might represent an important role for inflammation in the pathogenesis of atherosclerosis. It may be a potential biomarker of atherosclerotic inflammation and provide incremental information regarding the prediction of CAD besides traditional risk factors. We merit further investigation of CDK9 measurement in various clinical situations for identifying coronary atherosclerosis.

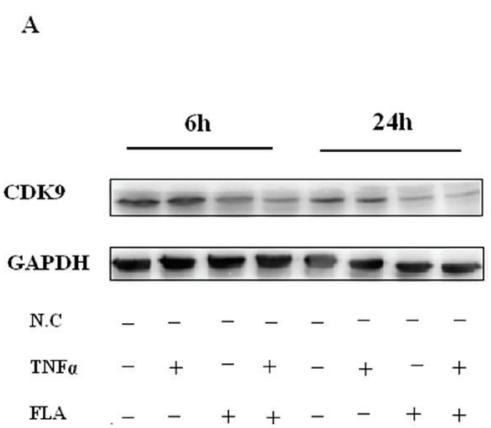

B

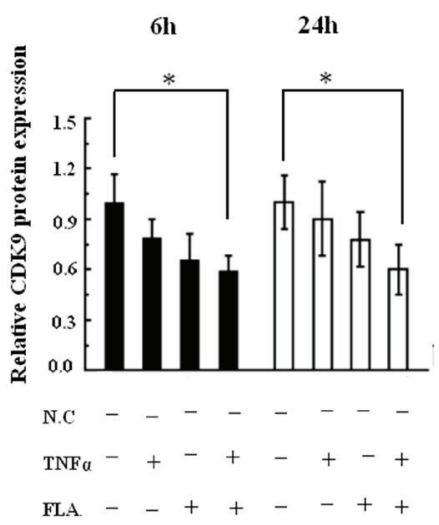

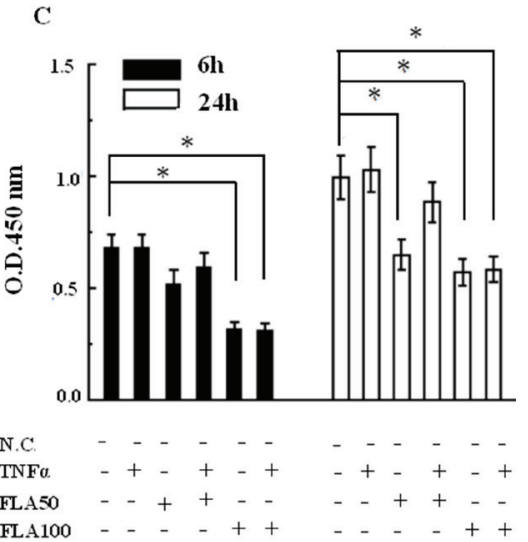

D

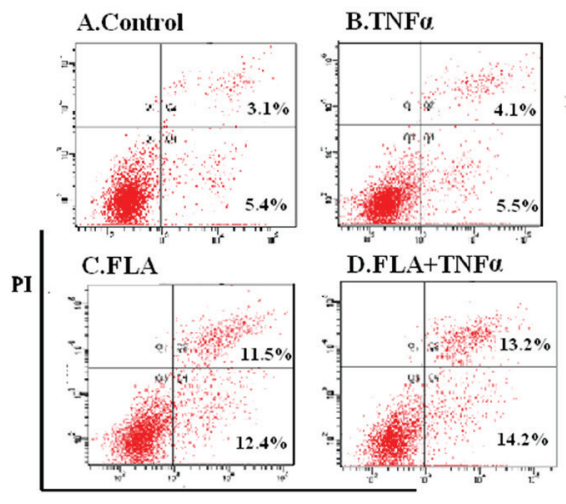

$\mathbf{E}$

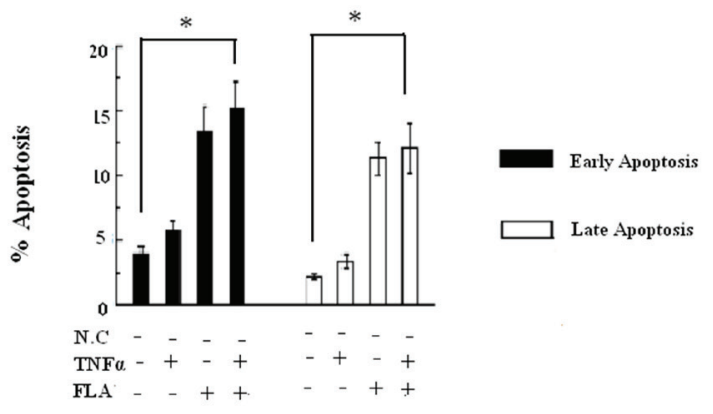

Figure 5: (A) Effects of FLA on the expression of CDK9 with or without TNF $\alpha$ stimuli. (B) The relative expression of CDK9 (Columns, means; Bars, \pm S.D; $* P<0.05$ ). (C) The CCK-8 assay showed that THP-1 cell proliferation was inhibited by FLA with or without TNF $\alpha$ stimulation. (D) Apoptosis measured by Annexin V/propidium iodide staining and flow cytometry. (E) Compiled percentage from three independent experiments of THP-1 cells treated with FLA with or without TNF $\alpha$ stimulation. Columns, means; Bars, \pm S.D; ${ }^{*} P<0.05$. 
In recent years, the anti-inflammatory effects of CDK9 inhibitors have been linked to its inhibition of cellular proliferation and induction of immune cell death [31]. Among these CDK9 inhibitors, FLA has shown a preference for inhibition of CDK9 over other CDKs [31]. FLA is an ATP analog that preferentially inhibits CDK9 kinase activity by a high-affinity interaction with its ATP-binding pocket [32]. FLA significantly inhibits inflammatory processes, such as dosedependent murine collagen-induced arthritis [10, 33]; murine hepatitis induced by concanavalin A [34] and catabolic effects of pro-inflammatory cytokines on cartilage [35]. Our result showed that in THP-1 cells, FLA suppressed CDK9 expression, caused inhibition of proliferation and potentiation of $\mathrm{TNF} \alpha$ induced apoptosis [36], demonstrated that FLA could inhibit THP-1 cell proliferation by targeting CDK9. But, it still needs many works to investigate possibility for the therapy of atherosclerotic CAD via CDK9 target.

\section{CONCLUSION}

CDK9 was found to be highly elevated in serum, monocytes and artery plaque samples of atherosclerotic CAD patients. Also, there was high infiltration of CD14 $4^{+}$ monocytes/macrophages within artery plaques correlated with the expression of CDK9. This indicated that CDK9 might be a potential biomarker of atherosclerotic inflammation and offer insights into the pathophysiology and targeted therapy for atherosclerotic CAD.

\section{MATERIALS AND METHODS}

\section{Study population}

Forty-three atherosclerotic CAD patients with symptoms of angina pectoris were included in the study after angiographic documentation of CAD from Qilu Hospital of Shandong University. Thirty-eight healthy volunteers without any evidence of atherosclerosis, CAD, hyperlipidemia, hypertension, diabetes mellitus or inflammatory disorders were enrolled from Jinan, Shandong Province, China and were used as the control group. This study was conducted in agreement with the Declaration of Helsinki and approved by the Human Ethics Committee of the School of Medicine, Shandong University.

\section{Serum collection, protein extracts and 2-D electrophoresis}

An aliquot of $5 \mathrm{~mL}$ from each peripheral blood sample was separated into serum fractions by centrifugation at $1000 \times g$ for $10 \mathrm{~min}$. Serum protein was harvested with the Albumin and IgG Removal Kit (Pierce, Thermo Scientific, Rockford, IL, USA) according to the manufacturer's instructions. The supernatant was subsequently collected and used for 2-D electrophoresis. Approximately $300 \mu \mathrm{g}$ of protein was suspended in a rehydration solution ( $8 \mathrm{M}$ urea, 2\% CHAPS, $65 \mathrm{mM}$ DTT, $0.2 \%$ pharmalyte $[\mathrm{pH}$ range $3-10]$ and $0.2 \%$ bromphenol blue) and applied to $18 \mathrm{~cm} \mathrm{pH} \mathrm{3-10} \mathrm{non-}$ linear Immobiline ${ }^{\mathrm{TM}}$ DryStrip Gels (GE Healthcare BioSciences, Pittsburgh, PA, USA) for isoelectrofocusing [37]. The isoelectrofocusing was performed using an Ettan IPGphor $^{\mathrm{TM}}$ Instrument (GE Healthcare Bio-Sciences), and proteins in the IPG strips were subsequently placed on a $12 \%$ uniform SDS-polyacrylamide gel. The gels were silver-stained and scanned with an Image Scanner in transmission mode, after which the image analysis was undertaken using 2-D PDQuest (Bio-Rad, Hercules, CA, USA).

\section{In-gel digestion and mass spetrometry analysis}

The in-gel digestion of proteins for mass spectrometry analysis has been reported previously [37]. Peptide mass analysis was performed using an AB4800 MALDI TOF/TOF mass spectrometer (Applied Biosystems, Foster City, CA, USA) after dissolving the tryptic peptide mixture with $0.5 \%$ trifluoroacetic acid. The mass spectra were externally calibrated with a peptide standard from Applied Biosystems. Based on NCBI human databases, the mass spectra were analyzed with a $50 \mathrm{ppm}$ mass tolerance by using GPS Explorer version 2.0.1 and Mascot version 1.9.

\section{Peripheral blood mononuclear cells (PBMCs) separation}

Whole blood samples were collected from atherosclerotic $\mathrm{CAD}$ patients and healthy control groups. The blood was aspirated into sterile glass tubes with sodium citrate as an anticoagulant to facilitate PBMCs separation by Ficoll-Hypaque gradient centrifugation. Cells were washed twice with phosphate buffered saline to remove residual platelets. The remaining aliquot $(200 \mu \mathrm{L})$ was placed into a microcentrifuge tube, frozen and kept at $-80^{\circ} \mathrm{C}$. The cold aggregation method was used with certain modifications to further separate the monocytes and lymphocytes [38]. Purity of the isolated monocytes was $90-95 \%$ as defined by flow cytometry with CD $14^{+}$ staining.

\section{RNA isolation and RT-PCR}

Total RNA was extracted from isolated PBMCs, lymphocytes and monocytes using the RNeasy Mini spin column kit (Qiagen, Inc., Valencia, CA, USA) according to the manufacturer's instructions. The RT-PCR was performed using the PrimeScript One Step RT-PCR kit version 2 (Takara Bio, Otsu, Japan). 
Sequences of specific primers for human CDK9 were 5'-GGAGACAGGGCATTTGAGTTA-3' and 5'-ATAGGA TTGTGGGTGGGTGAG- ${ }^{\prime}$, and those for GADPH as the internal control were 5'-AAGGTGAAGGTCGGAGTC AAC-3' and 5'-GGGGTCATTGATGGCAACAATA-3'.

\section{Immunological assays procedures}

The CDK9 level in serum sample was measured with Western blotting and ELISA (CDK9 antibody, SC13130, Santa Cruz Biotechnology, Inc, Dallas, TX, USA; GAPDH antibody, HMM04, Sangong, Shanghai, China; Human CDK9 ELISA Kit E-12517, HuiJia Biotechnology, Xiamen, China).

Hematoxylin and eosin (H\&E) staining of plaque tissue sections were performed according to standard procedures. Sections for immunohistochemistry staining were blocked sequentially with $3 \%$ hydrogen peroxide for $10 \mathrm{~min}$ and, $10 \%$ normal serum matching the host of the secondary antibody for $60 \mathrm{~min}$ at room temperature. Primary antibody against human CDK9 (1:800 dilution) or against human CD14 (1:100 dilution) was used. Later on, a standard rapid EnVision technique $\left(\mathrm{REAL}^{\mathrm{TM}}\right.$ EnVision $^{\mathrm{TM}}$ Detection System, Peroxidase/DAB+, Rabbit/Mouse, Code K5007, Dako, Denmark) was used to detect the protein conjugates and develop the color. The slides were viewed under $100 \times, 200 \times$ and $400 \times$ magnifications to define subcellular localization of the CDK9 and CD14.

\section{Proliferation and apoptosis analysis}

The monocytic acute leukemia cell line THP-1 (American Type Culture Collection, Manassas, VA, USA) was maintained in RPMI 1640 media supplemented with $10 \% \mathrm{FBS}$ at $37^{\circ} \mathrm{C}$ in a humidified atmosphere containing $5 \% \mathrm{CO}_{2}$. A colorimetric cell proliferation assay using the CCK-8-kit (Dojindo Laboratories, Kumamoto, Japan) was carried out according to the manufacturer's instructions. Briefly, THP- 1 cells at $1 \times 10^{5}$ per well were cultured in 96-well plates and treated with different concentrations of FLA (50 and $100 \mathrm{nM}$ ) for $6 \mathrm{~h}$ and $24 \mathrm{~h}$ with or without TNF $\alpha(50 \mathrm{ng} / \mathrm{mL})$ before measurement of O.D. $450 \mathrm{~nm}$. To explore the effect of CDK9 on THP-1 apoptosis, FLA (100 nM) was separately added to the culture for $6 \mathrm{~h}$ with/without $\mathrm{TNF} \alpha(50 \mathrm{ng} / \mathrm{mL})$. Apoptosis was measured using the Annexin V-FITC apoptosis detection kit (BD Biosciences Pharmingen, San Diego, CA, USA) and analyzed with a FACSCalibur flow cytometer and CellQuest Pro software (Becton Dickinson).

\section{Statistical analysis}

All continuous variables are expressed as means \pm standard deviation (SD), unless stated otherwise. All tests were performed 2-sided and a significance level of $P<0.05$ was considered to indicate statistical significance $(* P<0.05, * * P<0.01)$. All photo images of 2-D electrophoresis, Western blotting and immunohistochemistry staining represent at least three independent experiments.

\section{GRANT SUPPORT}

This work was supported by the National Science Foundation of China (81271198 and 81070223 to X. L.) and the State Program of National Natural Science Foundation of China for Innovative Research Group (81321061 to Y. G.).

\section{CONFLICTS OF INTEREST}

The authors have no conflicts of interest to disclose.

\section{REFERENCES}

1. Libby P. Inflammation in atherosclerosis. Nature. 2002; 420: 868-874.

2. Wei Y, Nazari-Jahantigh M, Neth P, Weber C, Schober A. MicroRNA-126, -145, and -155: a therapeutic triad in atherosclerosis? Arterioscler Thromb Vasc Biol. 2013; 33: 449-454.

3. Jiang Y, Wang HY, Cao HM, Wang CY, Zhang L, Wang H, Liu L, Li Y, Cai JH. Peripheral blood miRNAs as a biomarker for chronic cardiovascular diseases. Sci Rep. 2014; 4:5026.

4. Degraba TJ, Hoehn GT, Nyquist PA, Wang H, Kenney R, Gonzales DA, Kern SJ, Ying SX, Munson PJ, Suffredini AF. Biomarker discovery in serum from patients with carotid atherosclerosis. Cerebrovasc Dis Extra. 2011; 1:115-129.

5. Avgerinos ED, Kadoglou NP, Moulakakis KG, Giannakopoulos TG, Liapis CD. Current role of biomarkers in carotid disease: a systematic review. Int J Stroke. 2011; 6: 337-345

6. Maisel AS, Krishnaswamy P, Nowak RM, McCord J, Hollander JE, Duc P, Omland T, Storrow AB, Abraham WT, $\mathrm{Wu} \mathrm{AH}$. Rapid measurement of B-type natriuretic peptide in the emergency diagnosis of heart failure. N Engl J Med. 2002; 347:161-167.

7. Tsutamoto T, Kawahara C, Nishiyama K, Yamaji M, Fujii M, Yamamoto T, Horie M. Prognostic role of highly sensitive cardiac troponin I in patients with systolic heart failure. Am Heart J. 2010; 159:63-67.

8. Sedlacek H, Czech J, Naik R, Kaur G, Worland P, Losiewicz M, Parker B, Carlson B, Smith A, Senderowicz A. Flavopiridol (L86 8275; NSC 649890), a new kinase inhibitor for tumor therapy. Int J Oncol. 1996; 9: $1143-1168$.

9. Han Y, Zhan Y, Hou G, Li L. Cyclin-dependent kinase 9 may as a novel target in downregulating the atherosclerosis inflammation (Review). Biomed Rep. 2014; 2:775-779. 
10. Krystof V, Baumli S, Fürst R. Perspective of cyclindependent kinase 9 (CDK9) as a drug target. Curr Pharm Des. 2012; 18:2883-90.

11. Schmerwitz UK, Sass G, Khandoga AG, Joore J, Mayer BA, Berberich N, Totzke F, Krombach F, Tiegs G, Zahler S. Flavopiridol protects against inflammation by attenuating leukocyte-endothelial interaction via inhibition of cyclindependent kinase 9. Arterioscler Thromb Vasc Biol. 2011; 31:280-288.

12. de Azevedo WF, Jr, Canduri F, da Silveira NJ. Structural basis for inhibition of cyclin-dependent kinase 9 by flavopiridol. Biochem Biophys Res Commun. 2002; 293: 566-571.

13. Price DH. P-TEFb, a cyclin-dependent kinase controlling elongation by RNA polymerase II. Mol Cell Biol. 2000; 20: 2629-2634.

14. Romano G. Deregulations in the cyclin-dependent kinase-9related pathway in cancer: implications for drug discovery and development. ISRN Oncol. 2013; 305371.

15. Malumbres M, Pevarello P, Barbacid M, Bischoff JR. CDK inhibitors in cancer therapy: what is next? Trends Pharmacol Sci. 2008; 29:16-21.

16. Desai SR, Pillai PP, Patel RS, McCray AN, Win-Piazza HY, Acevedo-Duncan ME. Regulation of Cdk7 activity through a phosphatidylinositol (3)-kinase/PKC-iota-mediated signaling cascade in glioblastoma. Carcinogenesis. 2012; 33:10-19.

17. Bagella L, Stiegler P, De Luca A, Siracusa LD, Giordano A. Genomic organization, promoter analysis, and chromosomal mapping of the mouse gene encoding Cdk9. J Cell Biochem. 2000; 78:170-178.

18. Fu TJ, Peng J, Lee G, Price DH, Flores O. Cyclin K functions as a CDK9 regulatory subunit and participates in RNA polymerase II transcription. J Biol Chem. 1999; 274:34527-34530.

19. Simone C, Giordano A. Abrogation of signal-dependent activation of the cdk9/cyclin T2a complex in human RD rhabdomyosarcoma cells. Cell Death Differ. 2007; 14: 192-195.

20. De Falco G, Bellan C, D'Amuri A, Angeloni G, Leucci E, Giordano A, Leoncini L. Cdk9 regulates neural differentiation and its expression correlates with the differentiation grade of neuroblastoma and PNET tumors. Cancer Biol Ther. 2005; 4:277-281.

21. Bellan C, De Falco G, Lazzi S, Micheli P, Vicidomini S, Schurfeld K, Amato T, Palumbo A, Bagella L, Sabattini E. CDK9/CYCLIN T1 expression during normal lymphoid differentiation and malignant transformation. J Pathol. 2004; 203:946-952.

22. Malumbres M, Barbacid M. Cell cycle kinases in cancer. Curr Opin Genet Dev. 2007; 17:60-65.

23. De Luca A, De Falco M, Baldi A, Paggi MG. Cyclin T: three forms for different roles in physiological and pathological functions. J Cell Physiol. 2003; 194:101-107.

24. Weinmann H, Metternich R. Drug discovery process for kinase inhibitors. Chembiochem. 2005; 6:455-459.
25. Romano G, Giordano A. Role of the cyclin-dependent kinase 9-related pathway in mammalian gene expression and human diseases. Cell Cycle. 2008; 7:3664-3668.

26. Krystof V, Chamrad I, Jorda R, Kohoutek J. Pharmacological targeting of CDK9 in cardiac hypertrophy. Med Res Rev. 2010; 30:646-666.

27. Ramakrishnan R, Dow EC, Rice AP. Characterization of Cdk9 T-loop phosphorylation in resting and activated CD4 (+) T lymphocytes. J Leukoc Biol. 2009; 86:1345-1350.

28. Garriga J, Peng J, Parreno M, Price DH, Henderson EE, Grana X. Upregulation of cyclin T1/CDK9 complexes during T cell activation. Oncogene. 1998; 17:3093-3102.

29. Leucci E, De Falco G, Onnis A, Cerino G, Cocco M, Luzzi A, Crupi D, Tigli C, Bellan C, Tosi P. The role of the Cdk9/Cyclin T1 complex in T cell differentiation. J Cell Physiol. 2007; 212:411-415.

30. De Falco G, Leucci E, Onnis A, Bellan C, Tigli C, Wirths S, Cerino G, Cocco M, Crupi D, De Luca A. Cdk9/Cyclin T1 complex: a key player during the activation/differentiation process of normal lymphoid B cells. J Cell Physiol. 2008; 215:276-282.

31. Sekine C, Sugihara T, Miyake S, Hirai H, Yoshida M, Miyasaka N, Kohsaka H. Successful treatment of animal models of rheumatoid arthritis with smallmolecule cyclin-dependent kinase inhibitors. J Immunol. 2008; 180:1954-1961.

32. Chao SH, Price DH. Flavopiridol inactivates P-TEFb and blocks most RNA polymerase II transcription in vivo. J Biol Chem. 2001; 276:31793-31799.

33. Ni W, Ji J, Dai Z, Papp A, Johnson AJ, Ahn S, Farley KL, Lin TS, Dalton JT, Li X. Flavopiridol pharmacogenetics: clinical and functional evidence for the role of SLCO1B1/OATP1B1 in flavopiridol disposition. PLoS One. 2010; 5:e13792.

34. Zoja C, Casiraghi F, Conti S, Corna D, Rottoli D, Cavinato RA, Remuzzi G, Benigni A. Cyclin-dependent kinase inhibition limits glomerulonephritis and extends lifespan of mice with systemic lupus. Arthritis Rheum. 2007; 56:1629-1637.

35. Yik JH, Hu Z, Kumari R, Christiansen BA, Haudenschild DR. Cyclin-dependent kinase 9 inhibition protects cartilage from the catabolic effects of proinflammatory cytokines. Arthritis Rheum. 2014; 66:1537-1546.

36. Demidenko ZN, Blagosklonny MV. Flavopiridol induces p53 via initial inhibition of $\mathrm{Mdm} 2$ and p21 and, independently of p53, sensitizes apoptosis-reluctant cells to tumor necrosis factor. Cancer Res. 2004; 64:3653-3660.

37. Li X, Lu D, He F, Zhou H, Liu Q, Wang Y, Shao C, Gong Y. Cullin 4B protein ubiquitin ligase targets peroxiredoxin III for degradation. J Biol Chem. 2011; 286:32344-32354.

38. Cruz-Topete D, Jorgensen JO, Christensen B, SackmannSala L, Krusenstjerna-Hafstrom T, Jara A, Okada S, Kopchick JJ. Identification of new biomarkers of lowdose GH replacement therapy in GH-deficient patients. J Clin Endocrinol Metab. 2011; 96:2089-2097. 